\title{
Application of Safety Check List On Confidential Inspection
}

\author{
CHEN Hai-yan, GAO Jian-guang, XU Yun-fei \\ Shandong University of Science and Technology, CPC Committee \\ Office University Office, Shandong Qingdao 266590
}

\begin{abstract}
Confidential work is an important work to a company or a country. Confidential inspection is an effective way to strengthen security work. By studying problems existing in the confidential work in the current, the paper introduces a method in confidential inspection, which is safety check list (SCL). Practice has proved that safety check list is the most effective tool of safety inspection. This paper applied safety check list in confidential work's classified workplace environment inspection. This method will promote the standard construction of confidential inspection.
\end{abstract}

Keywords: Safety check list, Confidential- inspections, Application

\section{Instruction ${ }^{1}$}

Confidential work has always been an important work to the Party and the State. With the changing of international political economic structure, and the constantly adjusting the level of science and technology, the importance of confidential work has been gradually increased. China has never stopped researching on the confidential work, especially in recent years.

In 2003, Chen Ailing researched how to do the confidential work in the new period. She analyzed new situation which the security work faced. And she put forward some methods, such as strengthening security management, increasing the investment and security check

\footnotetext{
* Corresponding author. Tel.: +86

13853233472.

E-mail address:sdustchy@163.com
} 
work [1]. Hu Jinjun also did some research on problems and counter measures of enterprise security inspection in 2011 [2]. He did some analyses on the problem of security check work in enterprises. At the same time, he put forward eight solutions in confidentiality inspection. One of the methods was that it would be scientifically to determine the inspection standards. Jia Bing discussed security work in university [3]. He expressed that security work in university is an important component to the national security work. After analyzed the problems, he argued that strengthen security inspections would be taken out.

Upon the present studies, security check is one of the important means to security work. There are two kinds of security inspection, one is daily inspection, and another is professional inspection which is under the use of special tools. In this paper, one method used in daily inspection will be introduced. That is safety check list (SCL).

\section{Technique}

As one of the basic methods of safety system engineering, safety check list played major role in accident risk monitoring and feedback effect. SCL is one of the most basic system safety analysis methods, since 1920s this method had begun to be adopted, which is still used now. The application of SCL contains the ideas and principles of systems engineering. Safety check list, in fact, is a project list and memo for security check. In order to find out the unsafe factors in the system, the project list is with the form of questions, which compiled in order according to the system or subsystem.

Safety check list is a tool to check and diagnose in security management, which belongs to qualitative analysis and evaluation. Meanwhile it is also an effective method to identify potential risk factors. It is simple and practical, and it is very popular in the production site. After the introduction of safety system engineering in our country, safety 
check list is applied in the industry firstly.

\subsection{The types of safety check list}

According to the different objects and purposes in security check, the inspectors need to prepare a list of the various types of security check. Due to the different inspection cycle, the safety check list can be divided into regular safety inspection table and irregular safety inspection table; According to the different purposes of inspection, the safety check list can be divided into the design review safety check list, factory (mine) safe check table, workshop (area) with safe check table, shift and jobs with safety check list and professional safety inspection table, etc [4-6].

\subsection{The content and format of}

\section{safety check list}

Table1. The format of safety check list

\begin{tabular}{c|c|c|c}
\hline $\begin{array}{c}\text { Serial } \\
\text { number }\end{array}$ & Check items & Answers & Notes \\
\hline 1 & $\times \times \times \times \times \times$ & Yes & $\times \times \times$ \\
\hline 2 & $\times \times \times \times \times \times$ & No & $\times \times \times$ \\
\hline$\ldots$ & $\ldots \ldots$ & $\ldots$ & $\ldots \ldots$ \\
\hline
\end{tabular}

The simplest safety check list only has four columns, serial number, the project, answer (" yes ", "no" column) and note (indicate the measures, requirements or other items). (See Table1and Table 2) In order to improve the effect of inspection, columns can be installed to specific safety check list further. For example, we can increase one column of "standard and the requirements", by listing each inspection standards, requirements and the relevant provisions etc. So the inspectors and inspection will be clear to operate. It also can be add with other columns, such as "treatment" ,"date" and "handling suggestion", so as to people can solve the problems in time, and ensure the safety of the system. 
Table2. Safety check list of transport system

\begin{tabular}{c|l|c|l|l}
\hline $\begin{array}{c}\text { Serial } \\
\text { number }\end{array}$ & \multicolumn{1}{|c|}{ Check item } & $\begin{array}{c}\text { Check } \\
\text { result }\end{array}$ & $\begin{array}{l}\text { Handling } \\
\text { suggestion }\end{array}$ & Director \\
\hline 1 & $\begin{array}{l}\text { If the operating procedure in up } \\
\text { and down material is correct? } \\
\text { If the electric locomotive is } \\
\text { over speed? } \\
\ldots . . .\end{array}$ & & & \\
\hline
\end{tabular}

\section{Check time:}

\section{Inspector :}

\subsection{The application of safety} inspection table

It should be check project item by item according to safety inspection table. The result was expressed with "yes" or "no", and it also can be expressed with the symbol " $\sqrt{ }$ " or " $x$ ". Things, such as prevention measures and essential requirements, can be registered in the remarks column. If the list contains some columns, for example, "treatment suggestion" and "processing time", it should be written according to actual situation.

\subsection{The basis for safety check list}

Relevant rules, norms, rules, and standards. For example,
Production Safety Law, safety regulations in coal mine, etc. In confidential work, the most important law is Keep Secrets Law of the People's Republic of China (Secrets Act), which was revised in 2010.

\section{Experience of the enterprises} and institutions The experience was formed in safety management and production management for a long time in enterprises and institutions. Work experience can tell us that the focus of security inspection.

\section{Accident data}

It includes in the same field at home and abroad, with the type of accident data. 


\section{Result of the system safety analysis}

Using system safety analysis methods, such as fault tree analysis, event tree analysis, etc, it will find out each basic event that causes accident. The results of these analysis methods are the basis of SCL.

\section{Application}

Secrets Act stipulate that state organs and units shall implement the secrecy work responsibility system, perfect the confidentiality protection measures, carry out the secrecy publicity and education, strengthen the security check. Therefore, security check is one important part of state organs and enterprises. Based on the above introduction, security check consists of daily inspection and professional inspection. Here we will discuss the application of safety check list on daily confidential inspection.

There are a lot of works need to do in daily confidential inspection. There are many aspects need to inspection. For example, confidentiality rules and regulations, secret-related personnel, classified area and secrecy education and so on. The paper applied SCL on the inspection of classified area [7-9].

\subsection{Preparation}

I . The relevant information

We need information about the process, equipment, and raw materials, etc. It is important to collect process control parameters, the special equipment operating procedures, the physical and chemical properties of raw materials.

II . The relevant laws and regulations

The laws and regulations are mainly related to the safety, health and environment. The accidents harm caused by the past the consequences of safety, health and environment are also very important.

\subsection{Announcements}

I . The key contents in the check list should be specified.

II . The content of all kinds of check list should be based on different objects and try to avoid repetition 
III . The content of check list especially used in checking the should be clearly defined, environment of classified convenient for operation.

IV. All the unsafe factors that may workplace. (See Table3) These lead to accidents should be listed. confidential places usually are the key parts in inspection. It was It must be make sure that all kinds seemed very important whether of unsafe factors were found or the surrounding environment was eliminated in a timely manner.

$\mathrm{V}$. Inspectors should sign their name on the list after the check. Meanwhile, they should find out problems timely and provide to the relevant departments.

\subsection{Examples of application} safe or not. The main check items included the gate, the window, alarm system, monitoring equipment, fire extinguishers, etc. According to the check results, inspectors should put forward rectification measures.

In this paper, safety checklist was applicated in confidential work,

Table3. Safety check list of confidential places in environment

\begin{tabular}{|l|l|l|l|}
\hline Check items & $\begin{array}{c}\text { Check } \\
\text { result }\end{array}$ & $\begin{array}{c}\text { Rectification } \\
\text { measures }\end{array}$ & Director \\
\hline If equipped with iron gate? & & \\
If equipped with the anti-theft window? & & \\
If equipped with alarm system? & & \\
If equipped with monitoring equipment? & & \\
If equipped with fire extinguishers? & & \\
If equipped with fire control card? & & \\
If fire extinguishers properly sealed? & & \\
If the pressure (the weight) of fire & & \\
extinguishers is normal? & & & \\
If the alarm is in good condition? &
\end{tabular}




\begin{tabular}{|l|l|l|l|}
\hline Inspectors : & & Check time : & \\
\hline
\end{tabular}

2003.3

\section{Conclusion}

Safety check list is the most basic and common methods of safety management, not only can be used for daily safety management, also can be used for safety assessment. Practice has proved that safety check list can also be used in the confidential inspection, for example, in checking the environment of classified workplace.

If the SCL will be effective in routine safety management and evaluation, the key is whether the content or factors listed in the list is across-the-board, and whether the process of checking is according with the facts.

With the method of SCL, we can do more. It will promote the standard construction of confidential inspection.

\section{References}

[1] CHEN Ai-ling, "Study of keeping confidential work under the new period", Sci-Technology and Management, Pp 132- 134,
[2] HU Jian-jun, "Problems and solutions in confidentiality inspection in enterprise", Journal of sinopec management institute, Pp 47- 49, 2011.No1,Vol.13

[3] JIA Bing, "Discuss the problems and countermeasures that colleges and universities are faced in the current secrecy work", Reform \& Openning, Pp 164- 165, 2010. No1.

[4] ZHANG Zhi-hong, "Use of safety inspection table in safety and hygiene evaluation", Industrial safety and dust control, Pp13- 14, 1999.11.

[5] JIANG Zi-zhong, AN Yu-bao, CAO Rui-jun, "How draw up and application of the safety check table”, Chemical engineer, 2003.

[6] SUN Guang-min, “Attentions about application of safety check list", Safy, 2002

[7] GUO Ai-hong, LIU Ling-ling, DENG Shao-xu, "Position, function and application of the safety check list in safety evaluation", Petrochemical safety 
technology, Pp24- 27, 2006

[8] WANG Ping, LU Zhi-qiang,

JIA Dan, "On the standardization

workflow establishment of

security management", China

standardization, Pp101-104, 2013

[9] XU Jun, ZHANG Ning-xin,

"Innovative ideas and practice of secrecy - - Application of Southeast University", Chinese university science \& technology, 2013,12. 